\title{
Werner Nienhueser*
}

\section{Flexible Work $=$ Atypical Work $=$ Precarious Work? Introduction to the Special Issue}

During the last decade, flexible work arrangements and so-called "atypical", "new" or "non-standard" forms of employment (Kalleberg 2000) have constituted a central element in the debate on the future of work and employment relations (see also Bosch 2004). The main two questions of this special issue are, very generally and simply speaking: What are the prerequisites and the consequences of new or atypical forms of employment at the individual level, at the firm level and at the level of society? In addition, how do different regulations or institutions mediate the consequences?

There are many unanswered, more specific questions: What is an adequate definition of atypical employment? How widespread are different forms of atypical employment? Which different regulations do we find in different countries, and what are the consequences of various regulations on the working conditions of the employees, respectively self-employed persons? What are the causes of the frequency and growth of different forms of non-standard employment? What do we mean by precariousness, how can we measure it, does it go systematically and under all circumstances hand in hand with flexible work? In the vast and widely dispersed literature, one finds at least two streams of arguments: On the one hand, flexible work arrangements (e.g. part-time work, temporary agency work, self-employment, etc.) are discussed as a means of enhancing the capability of firms to adapt to changing market conditions, to satisfy the preferences of the workers and to decrease unemployment. These arguments are found primarily in management-orientated research, in business administration, and partly in economics. On the other hand, flexible work arrangements are seen as precarious, leading to unstable employment, low wages, bad working conditions, and to the erosion of the welfare state. This perspective is not only, but mainly represented in sociology, also in political sciences or from critical-orientated researchers in business administration. However, these two positions do not exclude each other (see also Martin/Nienhüser 2002). One could say: it depends. But on what? Under which circumstances are flexible work arrangements precarious? What are possible conditions under which atypical employment serves employers, employees and the society equally? Do we have to differentiate between precariousness in the long and short run? Is it possible to have the advantages of flexibility (for the firms) and, at the same time, avoid possible negative effects (for the workers)? In this special issue, one finds a variety of articles with important answers to these questions, most of them addressing the employment relationship from a meso level, focussing on issues between individual workers and the firm on the one hand and the industrial relations (societal) level on the other hand. All articles are based on empirical research, drawing on con-

Prof. Dr. Werner Nienhueser, University of Duisburg-Essen, Institute of Human Resource Management, Department of Business Administration, Economics, Business Computing and Informatics, Universitätsstr. 12, D - 45117 Essen, Phone: ++49 2011833622 / 183 2260, Fax: ++49 201183 2283, e-mail: werner.nienhueser@uni-essen.de. 
ceptual and theoretical underpinnings as well. The articles gather, and I see this as an advantage, a wide pallet of methodical perspectives. Widely invested secondary analyses of official data, "thick descriptions" (Clifford Geertz) in the form of case studies, multivariate analyses using survey data. This variety is suitable for the differentiated question and the complexity of the phenomenon, and can only extend and enrich the field of research. Now, however, let me turn to the individual contributions.

Berndt Keller and Hartmut Seifert analyse in their invited paper the connection between atypical employment and flexicurity, providing us with important foundations for the understanding of atypical or flexible employment forms. They refer, primarily, in their empirical and institutional based statements to the context in Germany, however, their hypotheses, findings and practical suggestions reach beyond this connection. Their starting point is the construct of "normal work" defined by the following key aspects: permanent employment contract, compulsory social insurance contributions, full-time working and corresponding pay, and a full overlap between working and employment. Based on these criteria, they identify the following forms of atypical employment: part-time work, fixed-term employment, temporary and agency work and new forms of self-employment. Secondly, Keller und Seifert supply the reader with a clarification of the question: What can we mean with flexibility if we use this term? They use the OECD's typology of forms of flexibilisation as a starting point, in order to place the different forms of atypical employment. Thirdly, Keller und Seifert give a thorough and probably the most current view on the state of the frequency of the different forms of "non-standard work" in Germany. Fourthly, and very importantly, the article introduces the concept of flexicurity and identifies strategies for reducing the risks of flexible forms of employment. Regulation, either by legislation or by collective agreements, is discussed as one such option.

Zeenobiyah Hannif and Felicity Lamm concentrate on the issue of precariousness of atypical work. They introduce and use for an empirical analysis of call centre work in New Zealand the so-called "Tucker" model, a list of ten indicators of precariousness. These indicators form some kind of scale used for measuring the phenomenon precariousness empirically. The indicators are worth a mention already at this point because there are not many approaches of this kind. A job is precarious, if the job can be terminated with little or no prior notice by the employer, if the hours of work are uncertain or can be changed at will by the employer, if earnings are uncertain or irregular, if the functions of the job can be changed at will by the employer, if there is no explicit or implicit contract for ongoing employment, if there is, in practice, no protection against discrimination, sexual harassment or unacceptable working practices, if the job is low income, if there is little or no access to "standard" employment benefits such as sick leave, if there is limited or no opportunity to gain and retain skills through access to education and training, if the job is dangerous or unhealthy. The paper not only discusses the strengths and limitations of the indicators but also applies them to the call centre context. Two call centres are selected and analysed using a qualitative, case study research approach. The results indicate evidence of precariousness in both call centres. In one call centre, precariousness could be detected on 9, in the second case on 7 of the 10 indicators. Deeper analyses show that the more atypical an employment arrangement is the more precarious are the working conditions. 
John Burgess, Julia Connell and Erling Rasmussen concentrate on agency work, one of the most flexible employment forms, and employment precariousness in Australia and New Zealand. First, the article clarifies the relationship between agency employment and precariousness. To what extent does it lead to precarious employment? What moderating factors reduce this precariousness? Burgess et al identify agency work as an extreme form of labour commodification, leading to insecurity and precariousness. Secondly, they ask what limits the expansion of (precarious) agency employment. Surprisingly, even in a context of an "unregulated wild west approach" (Rasmussen/Lind/Visser 2004: 164) as it is the case in New Zealand and Australia, we find nearly the same low proportion of agency work as in other relatively strong regulated countries. The reasons for this are: On the one hand, agency work offers many of advantages to employing organisations mainly associated with labour flexibility. But despite its flexibility advantages, there are, on the other hand, several factors that limit the expansion of agency employment: in particular, the availability of other flexible, functionally equivalent forms of employment and - last but not least and often overlooked - the ongoing need for secure and long-term employment relationships by the employers (see also Burgess/Connell 2004).

Lars $W$. Mitlacher's analysis focuses on the ambiguities resulting from the tripartite arrangement of temporary agency work. His main proposition states that the increasing use of temporary agency work (in Germany) changes the nature of the employment relationship and affects human resource management of client companies. Besides developing arguments for this proposition, he discusses another hypothesis regarding the theoretical level in connection to the empirical level: the problematic consequences of the use of temporary agency workers on the human resource management have been overlooked according to Mitlacher because of the dominance of new institutional economic approaches in the analysis of temporary agency work. Especially commitment and identification with the client company are important elements, not only in the employment relationship in general, but also in the - in a contractual sense: indirect - relationship between agency workers and the client firm. Problems are caused by the addition of a third party, the agency, besides those of employer and employee resulting in additional complexity, uncertainty, and endangering the quality of the exchange relationship. Especially in a situation when it becomes important to creating commitment and loyalty, human resource management should take into account the special needs of temporary agency workers in order to avoid the violation of the psychological contract.

Claudia Weinkopf and Karen Jaehrling address the relationship between low-skill jobs and atypical employment. In the literature, we very often find the implicit or explicit assumption that the skill requirements for most of the workers in atypical employment are very low and/or very unspecific. The literature does certainly not ignore that, e.g., so-called "freelancers" are frequently exceptionally highly qualified. However, the term "atypical" is often, nevertheless, mentally associated with the attribute "low-skill" associated. This has certainly its reasons. Transaction cost theory, for instance, tells us that in the case of unspecific skill requirements and easy performance measurement, we will observe more externally flexible employment arrangements and often, if not always, low-skill jobs. Weinkopf und Jaehrling question the traditional assumptions 
about low-skill jobs and ask whether and to what extent jobs in several service industries are "jobs that anyone can do". Their analysis is based on empirical studies on recruitment problems and low-skill jobs in the literature and on their own case studies of recruitment into low-skill jobs in several service industries. First, these studies taken together indicate that job requirements are changing in recent years and becoming more differentiated, which would suggest that low-skill work is in flux. A second result is that firms adopt a range of different recruitment strategies and forms of employment; flexible and atypical employment relationships and so-called mini-jobs play an important role in this range of strategies.

The article by Christian Pfeifer deals with the determinants and consequences of different forms of flexible employment. His paper is based on hypotheses derived from economic theories, in particular, from internal dual labour markets theories. One main idea of these theories is that a flexible periphery of workers is used to buffer the highly valuable core employees against the risks of changing demands for labour. Pfeifer uses data from the Hannover Establishment Panel, which covers approximately one thousand establishments every year from Lower Saxony with at least one employee. His paper examines empirically, firstly, what forms and instruments firms use to react flexibly to demand-induced output variations, and whether they are used complementary or substitutable. Secondly, the determinants of fixed-term contracts and temporary agency work are analysed. Thirdly, the article deals with the question of the impact of flexible employment forms on job security and job stability of regularly employed workers. Empirical evidence shows that the most frequently used instruments could be attributed to internal numerical flexibility, i.e., working time flexibility, and that there is - with few exceptions - a rather complementary than substitutable relationship between the instruments. In line with an argument derived from dual labour market theory is the observation that an expected positive development of sales leads to a higher proportion of fixed-term contracts. Contrary to propositions of dual labour market theory is the result that temporary employment does not decrease the number of layoffs and quits.

Is it possible - concluding this introduction - to relate the outlined results to the leading questions of this collected volume and supply unambiguous answers? For the purpose of empirical and theoretical generalisations, the answers may not be satisfying enough as the spectrum of the forms of atypical employment forms is too large, the institutional differences are too massive and the theories and data are (still) not extensive enough. Nevertheless, we are (at least I am) informed about different, and in its theoretical context, precise definitions of atypical employment and forms of flexibilisation. We know more about the determinants of atypical employment. We learn that - in most but not in all cases - atypical and flexible work is in the same hand precarious, we see, precariousness depends in particular on different forms of regulations at the societal, industry or firm level. Moreover, findings point to the fact that the shortterm advantages of flexibility, particularly if they go with precarious working conditions, can turn, medium term or long term, into problems, also for the management. We know a great deal, even when it is not enough. 


\section{References}

Bosch, G. (2004): Towards a New Standard Employment Relationship in Western Europe. In: British Journal of Industrial Relations, 42(4): 617-636.

Burgess, J./Connell, J. (2004): International perspectives on temporary agency work. London u.a.

Kalleberg, A. (2000): Nonstandard Employment Relations: Part-time, Temporary and Contract Work. In: Annual Review of Sociology, 26: 341-365.

Martin, A./Nienhüser, W. (Hg.) (2002): Neue Formen der Beschäftigung - neue Formen der Personalpolitik? München/Mering.

Rasmussen, E./Lind, J./Visser, J. (2004): Agencies, Agency Workers and Atypical Employment in New Zealand. In: Burgess, J./Connell, J. (eds.): International Perspectives on Temporary Agency Work. London u.a.: 164-178. 